\title{
Fingertip Amputation Reconstruction with VY Advancement Flap: Literature Review and Comparative Analysis of Atasoy and Kutler Flaps
}

\author{
Sourabh Shankar Chakraborty ${ }^{1}$, Prakash Chandra Kala ${ }^{1^{\star}}$, Ranjit Kumar Sahu ${ }^{2}$, \\ Pawan Kumar Dixit ${ }^{1}$, Deepti Katrolia ${ }^{1}$, Suresh Kotu ${ }^{1}$
}

\footnotetext{
1. Department of Burns and Plastic Surgery, All India Institute of Medical Sciences, Jodhpur, India

2. Department of Burns and Plastic Surgery, All India Institute of Medical Sciences, Bhubaneswar, India
}

\section{${ }^{*}$ Corresponding Author: \\ Prakash Chandra Kala}

Department of Burns and Plastic Surgery, All India Institute of Medical Sciences, Jodhpur, India

Tel.: +91-8460952204

Email: drpckala@gmail.com

Received: 2021.02.5

Accepted: 2021.09.12

\section{ABSTRACT}

\section{BACKGROUND}

Many different flaps had been described to cover exposed bone in fingertip amputations and injuries. The variants of VY advancement flap, by far the simplest, had proven to render good functional and aesthetic outcome. We aimed to revisit and compare the various VY advancement flaps in fingertip reconstruction.

\section{METHODS}

PubMed [MEDLINE] database was searched for VY advancement flap in fingertip reconstruction. Demographic and outcome data were extracted from relevant studies and comparative analysis was made. Patients with fingertip amputations undergoing reconstruction by either Kutler of Atasoy flaps in our institute, were assessed for sensory recovery, cold intolerance, joint's range of motion, and aesthetic outcomes and results were analysed.

\section{RESULTS}

Among the 744 articles, 32 citations went full text review and were included, while data of 13 articles were tabulated. Weighted mean of 2PD in Kutler and Atasoy estimated to be 6 and $7.5 \mathrm{~mm}$ respectively. Hook nail deformity was in $29 \%$ and $35 \%$, pain was present in $71 \%$ and $30 \%$ patients, in Kutler and Atasoy flaps respectively. Forty fingertips with Allen type II/III were reconstructed. Sensory outcomes of Atasoy flap and Kutler flaps were better than the previous study results. Four patients had cold intolerance. All patients achieved satisfactory aesthetic outcome.

\section{CONCLUSION}

Over time, VY advancement flap have been successfully used for reconstruction of Allen type II-IV fingertip amputations, as suggested by the good sensory, functional and aesthetic outcomes.

\section{KEYWORDS}

Kutler flap; Atasoy flap; Triangular flap; V-Y flap; Fingertip amputation

\section{Please cite this paper as:}

Chakraborty SS., Kala PC., Sahu RK, Dixit PK., Katrolia D., Kotu S. Fingertip Amputation Reconstruction with VY Advancement Flap: Literature Review and Comparative Analysis of Atasoy and Kutler Flaps. World J Plast Surg. 2021;10(2):8-17.

doi: $10.29252 /$ wjps.10.3.8 


\section{INTRODUCTION}

Fingertip amputations are most common injuries of the hand and extremely disabling. Apart from pain, patients lose significant time from work. The ideal procedure should cover defect with padded, nontender, sensate skin; and must preserve length, grip strength. It should also be cosmetically appealing and have minimal morbidity to donor site. Across the literature numerous techniques have been well described for fingertip reconstruction from healing with secondary intention, free skin grafts, bone shortening and primary stump closure to various flaps namely, cross finger, thenar, abdominal, heterodigital/homodigital neurovascular island flaps, unilateral/ bilateral VY plasty, volar advancement, rotation flaps, perforator based and even free flaps ${ }^{1}$. Every procedure have shown promising outcomes up to varying degrees, while sharing few innate disadvantages, like donor site morbidity, technically demanding surgery and so on. Therefore, a common consensus on the best technique for fingertip reconstruction is very unlikely.

We aimed to explore the potential and role of a simple yet successful procedure, the V-Y advancement flap, in fingertip reconstruction.

\section{METHODS}

PubMed [MEDLINE] database was searched on September 2020 using the MeSH terms: "Tranquilli leali flap[MeSH Terms] OR Kutler flap[MeSH Terms] OR Atasoy flap [MeSH Terms] OR Triangular flap[MeSH Terms] OR V-Y flap[MeSH Terms] AND
Fingertip amputation[MeSH Terms] OR fingertip injury[MeSH Terms]". Studies were limited to human, published in English language from 1947 to 2020 . The titles and abstract were reviewed manually to identify appropriate studies. In cases of unclarity, full test was reviewed. References of appropriate articles were also screened to identify additional related studies not obtained from original search. From the final included articles data was extracted and tabulated, namely study sample, outcomes and complications, and a comparative analysis was done. Weighted mean was calculated by dividing the sum of total mean values of each parameter in all studies (obtained by multiplying mean with sample size) by total sample size of all studies.

This study was carried out prospectively from September 2018 to August 2020. The study was approved and ethical clearance was obtained from Institutional Review Board. AIIMS/IEC/2019/834 (All India Institute of Medical Sciences, Jodhpur, Institutional Ethical Committee). Patients' inclusion and exclusion criteria are given in Table 1. Irrespective of age, sex and type of injury, patients were included after taking informed consent for surgery and willingness to be part of the study.

\section{Surgical procedure}

Defects were debrided, irrigated and margins were trimmed under tourniquet control. Fingertips were reconstructed by advancement of either volar triangular flap, Atasoy flap or bilateral triangular flap, Kutler flap with standard technique. Incisions were carried down up to subcutaneous level, and no undermining was done to preserve the terminal branches of proper digital arteries. Distal

Table 1: Inclusion and exclusion criteria

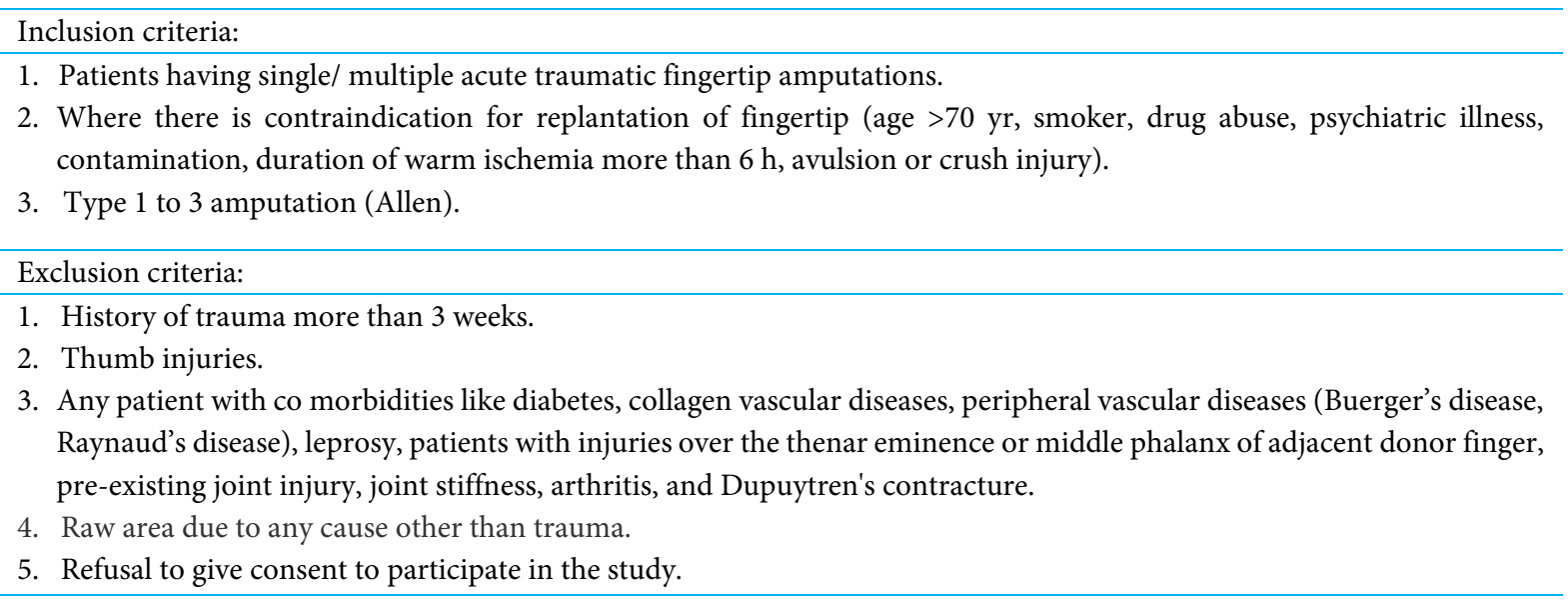




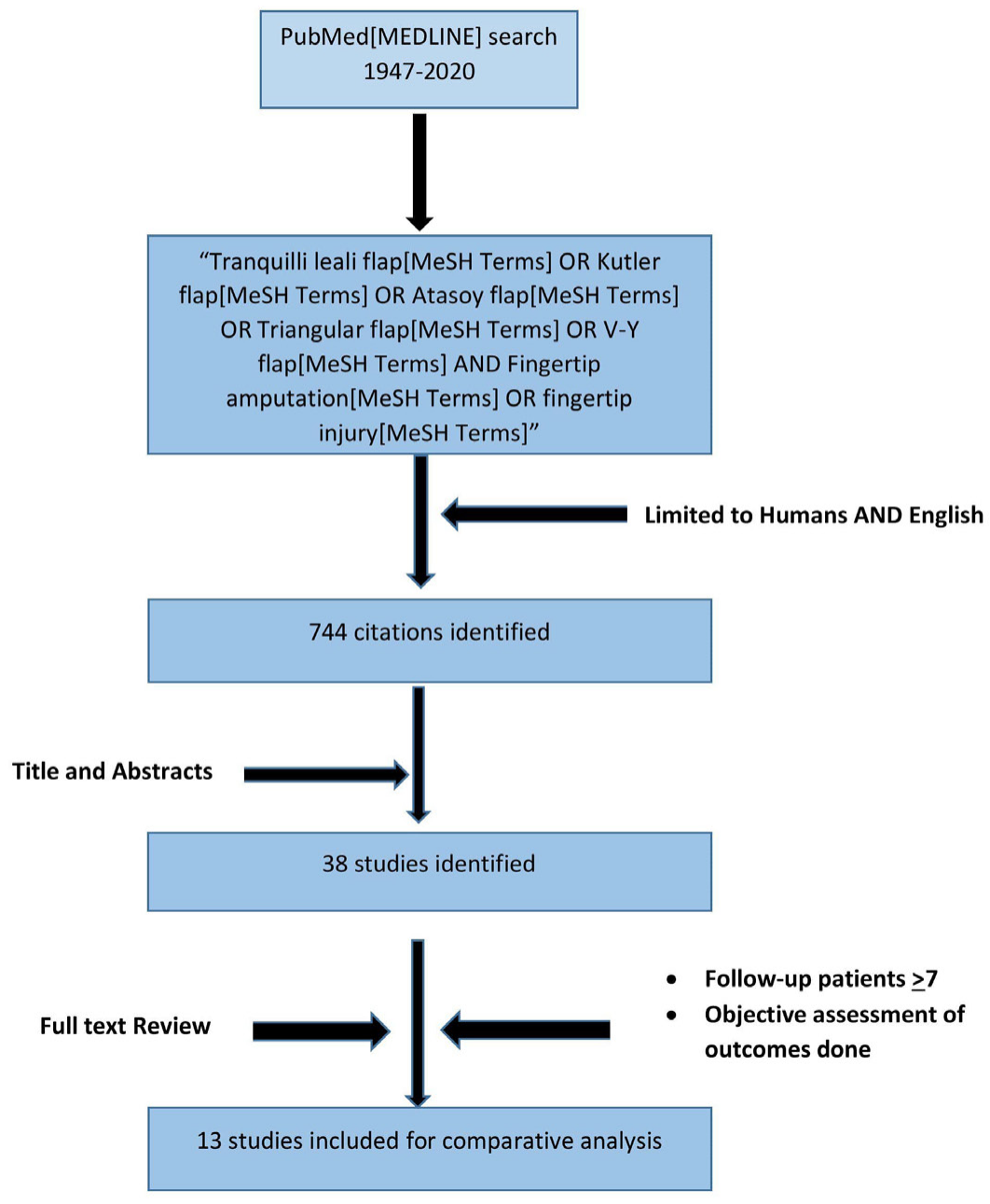

Fig. 1: Flow chart of literature search

interphalangeal joint crease was not breached. Patients were then systematically followed up.

\section{Assessment parameters}

Objective neurosensory assessment by static twopoint discrimination (2PD) of reconstructed fingertip (only the best response across the flap) and contralateral fingertip was done. Cold intolerance of reconstructed and contralateral fingertip were recorded using Cold Intolerance Symptom Severity (CISS) questionnaire ${ }^{2}$. Functional outcome by passive range of motion ( $\mathrm{ROM}$ ) of reconstructed and contralateral fingers, at distal and proximal interphalangeal (DIP, PIP) joints were measured using goniometer. Patients' aesthetic satisfaction was evaluated by Numerical Rating Scale (NRS) for reconstructed fingertips ${ }^{3}$. All these parameters were recorded by a single observer. All the data including demography of included patients, mode and type of injury, delay in intervention, complications in post- operative and follow up period, duration of follow up and values of sensory, functional and aesthetic parameters were recorded in Microsoft Excel. $P$-value was calculated using unpaired t-test.

\section{RESULTS}

The PubMed search produced 744 articles. After title and abstract review 32 citations were identified, that went full text review and were included in this article (Figure 1). Thirteen articles, that had a minimum of 7 follow-up patients on whom outcomes were measured objectively, were tabulated (Table 2). The weighted mean of 2PD in Kutler and Atasoy flaps were 6 and $7.5 \mathrm{~mm}$ respectively, while cold intolerance present in $39 \%$ and $54 \%$ in the two groups respectively. Hook nail deformity was in $29 \%$ and $35 \%$, pain was reported in $71 \%$ and $30 \%$ patients, in Kutler and Atasoy flaps respectively.

Overall, 34 patients were included in this study 


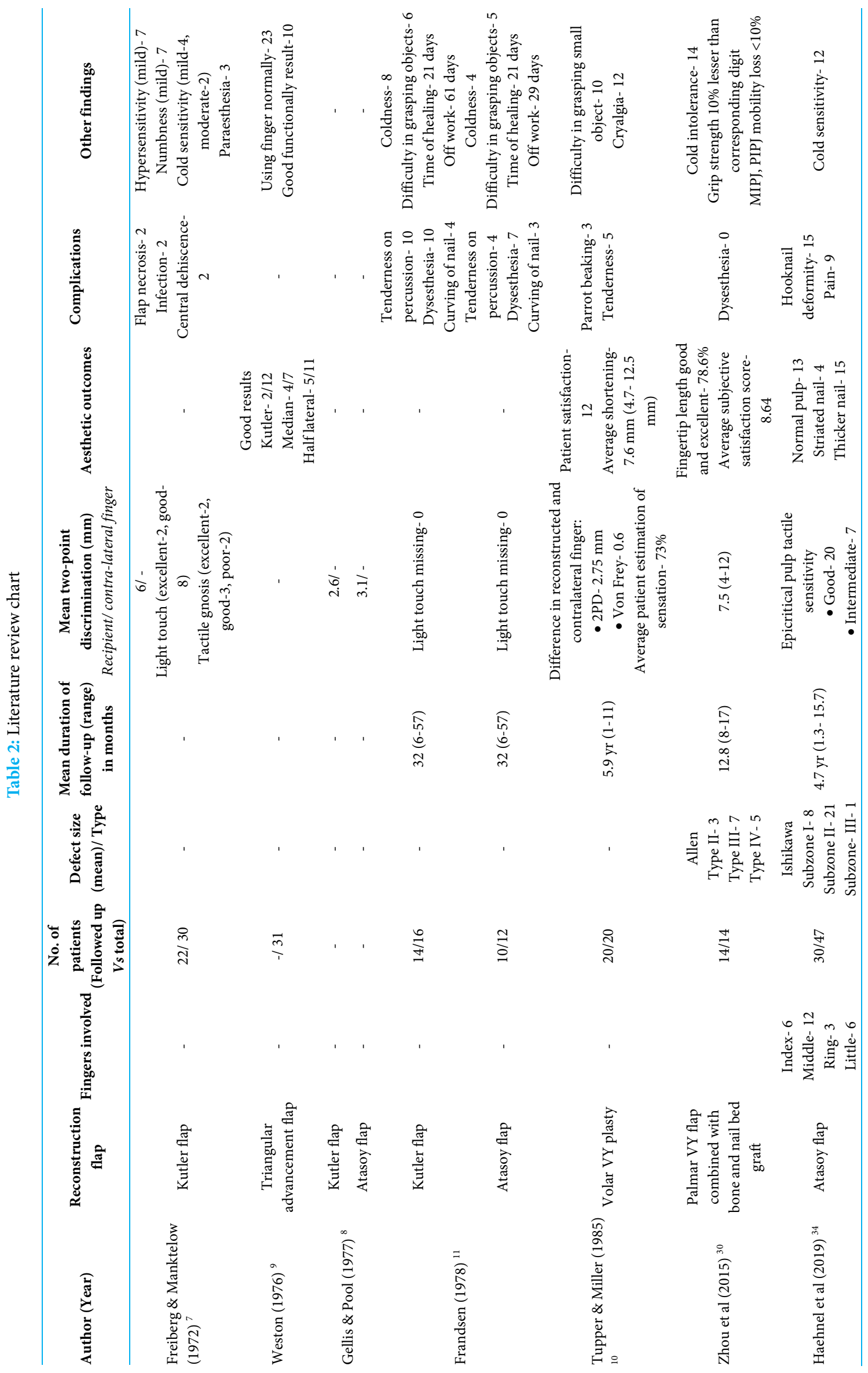




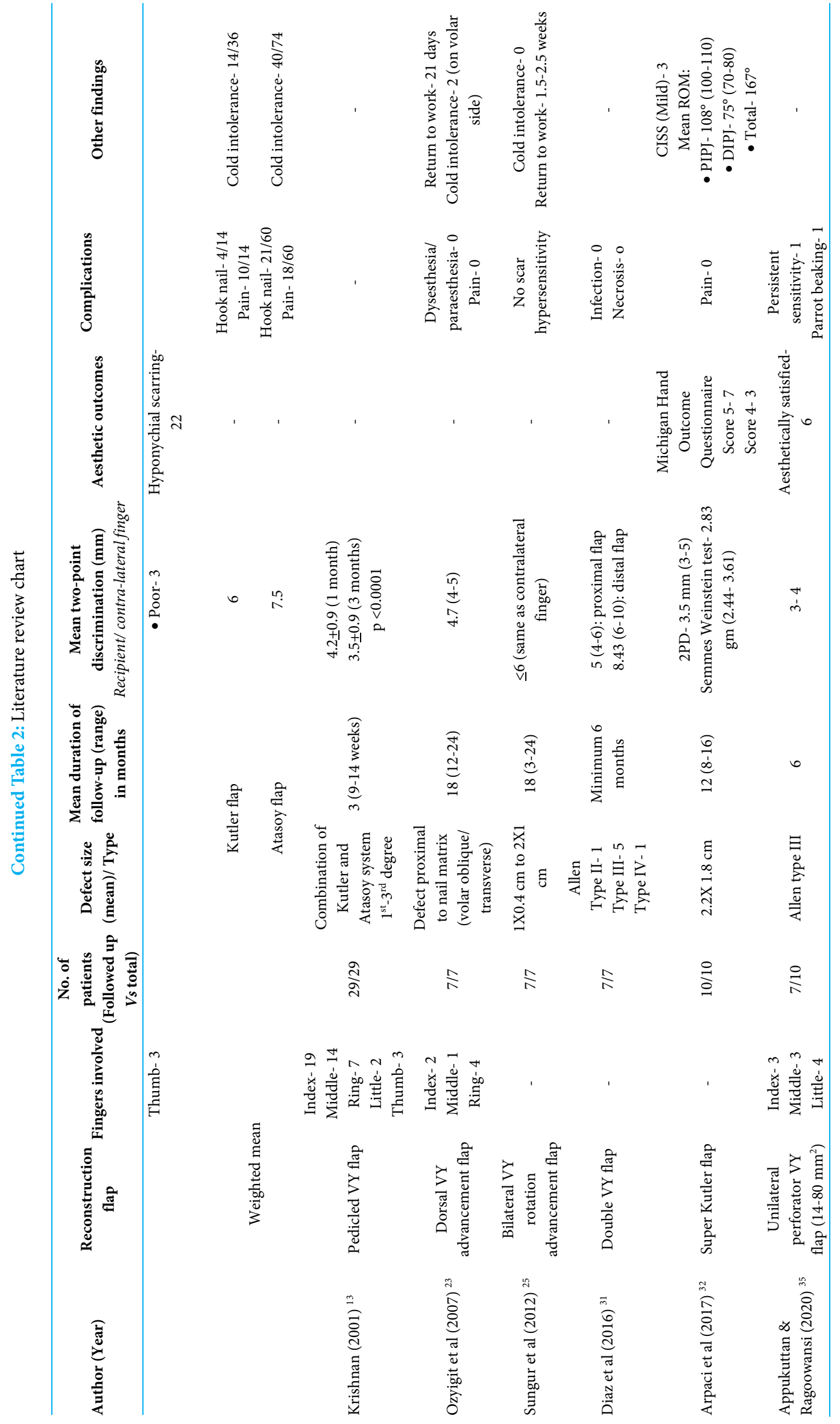


Table 3: Study results (comparing the flaps)

\begin{tabular}{|c|c|c|c|c|c|c|}
\hline & \multicolumn{2}{|c|}{ Atasoy flap group } & \multicolumn{2}{|c|}{ Kutler flap group } & \multirow{2}{*}{$P$-value } \\
\hline & & Mean (SD) & Range & Mean (SD) & Range & \\
\hline \multicolumn{2}{|c|}{ Number of fingertips reconstructed } & 22 & - & 18 & - & - \\
\hline \multicolumn{2}{|c|}{ Age of patients (yr) } & 27.3 & $9-51$ & 28.7 & $4-40$ & - \\
\hline \multirow{4}{*}{$\begin{array}{l}\text { Number of fingertip } \\
\text { reconstructed }\end{array}$} & Index & 8 & - & 6 & - & - \\
\hline & Middle & 8 & - & 4 & - & - \\
\hline & Ring & 6 & - & 4 & - & - \\
\hline & Little & 0 & - & 4 & - & - \\
\hline \multirow{2}{*}{$\begin{array}{l}\text { Type of injury (Allen } \\
\text { types) }\end{array}$} & Type II & 10 & - & 6 & - & - \\
\hline & Type III & 12 & - & 12 & - & - \\
\hline \multicolumn{2}{|c|}{ Time of presentation (days) } & 0.18 & $0-1$ & 0.22 & $0-1$ & - \\
\hline \multicolumn{2}{|c|}{ Flap completely survived } & 22 & - & 16 & - & - \\
\hline \multicolumn{2}{|c|}{ Follow up period (months) } & $9.27 \pm 1.70$ & $6-12$ & $11.78 \pm 2.51$ & $7-15$ & - \\
\hline \multirow{2}{*}{$\begin{array}{l}\text { Static two-point } \\
\text { discrimination (mm) }\end{array}$} & $\begin{array}{l}\text { Reconstructed } \\
\text { finger }\end{array}$ & $5.27 \pm 1.75$ & $4-10$ & $4.78 \pm 2.10$ & $3-10$ & 0.4214 \\
\hline & $\begin{array}{l}\text { Contralateral } \\
\text { finger }\end{array}$ & $3.45 \pm 0.51$ & $3-4$ & $3.56 \pm 0.51$ & $3-4$ & 0.5372 \\
\hline \multirow{2}{*}{ CISS score } & $\begin{array}{l}\text { Reconstructed } \\
\text { finger }\end{array}$ & $16.64 \pm 6.18$ & $10-30$ & $16.67 \pm 5.94$ & $12-30$ & 0.9876 \\
\hline & $\begin{array}{l}\text { Contralateral } \\
\text { finger }\end{array}$ & $10.91 \pm 4.08$ & $6-20$ & $12 \pm 3.25$ & $7-18$ & 0.3638 \\
\hline \multirow{2}{*}{$\begin{array}{l}\text { Passive ROM } \\
\text { (Reconstructed finger) }\end{array}$} & DIPJ & $58.18 \pm 7.95$ & $50-70$ & $60.56 \pm 7.05$ & $50-70$ & 0.3294 \\
\hline & PIPJ & $100.91 \pm 6.84$ & $90-110$ & $105 \pm 4.85$ & $95-110$ & 0.0393 \\
\hline \multirow{2}{*}{$\begin{array}{l}\text { Passive ROM } \\
\text { (Contralateral finger) }\end{array}$} & DIPJ & $64.55 \pm 6.71$ & $50-75$ & $61.11 \pm 7.58$ & $50-70$ & 0.1371 \\
\hline & PIPJ & $100.45 \pm 5.96$ & $90-110$ & $102.78 \pm 5.48$ & $95-110$ & 0.2114 \\
\hline \multicolumn{2}{|c|}{ NRS of reconstructed flap } & $7.64 \pm 1.09$ & 5-9 & $7.22 \pm 1.59$ & 6-9 & 0.3369 \\
\hline
\end{tabular}

and 40 fingertips were reconstructed with either Atasoy or Kutler flap. All patients suffered injury at their workplace (factory worker, farmer) except four children, two male and two female. Mostly presented to us on the same day, except 4 patients who reached after one day. Twenty-two fingertips had Allen's type 3 injury while 16 had Allen's type 2 injury. Moreover, 22 of the fingertip reconstruction was done by Atasoy Flap, while 18 done by Kutler flap. 2 of the Kutler flap underwent partial necrosis, conservatively managed. After a mean follow-up period of 9 months patients undergoing Atasoy flap achieved a mean $5.27 \mathrm{~mm}$ of static $2 \mathrm{PD}(P=0.0003)$, while the Kutler flap group achieved mean 2PD of $4.63 \mathrm{~mm}$ after a mean interval of 11 months $(P=0.0155) . P$-values suggests statistically significant difference between sensations of reconstructed fingertip with control fingertip in both groups. The passive ROM at DIPJ in Atasoy flaps is hampered statistically significantly $(P=0.0002)$, while in Kutler flap this difference between reconstructed and control finger is not statistically significant $(P=0.71)$. However, passive ROM at PIPJ in either flaps is not significantly affected ( $P=0.81$ in Atasoy flap, 0.13 in Kutler flap). Only four fingers in 4 patients had CISS score of 30 , suggested as threshold of pathological cold intolerance $e^{2}$. The aesthetic outcome in both groups were similar $(P=0.34)$ (Table 3, Figures. 2 \& $3)$.

\section{DISCUSSION}

The first full thickness VY advancement flap was described by Tranquilli-Leali in 1935 for fingertip reconstruction ${ }^{4}$. It was Kutler, in $1947^{5}$ who first described bilateral VY advancement flap for reconstruction of fingertip amputation. Two triangular skin flaps from each side of the stump are advanced to cover the transverse central defect and closed in a Y-pattern. Skin incision is carried out up to subcutaneous tissue. He quoted that it gives a smooth contour to the fingertip and fingertip becomes non-tender. A modified triangular volar flap was introduced and performed volar VY plasty in 64-fingertip amputations ${ }^{6}$. None of the 56 patients who were followed up had any serious complications, 

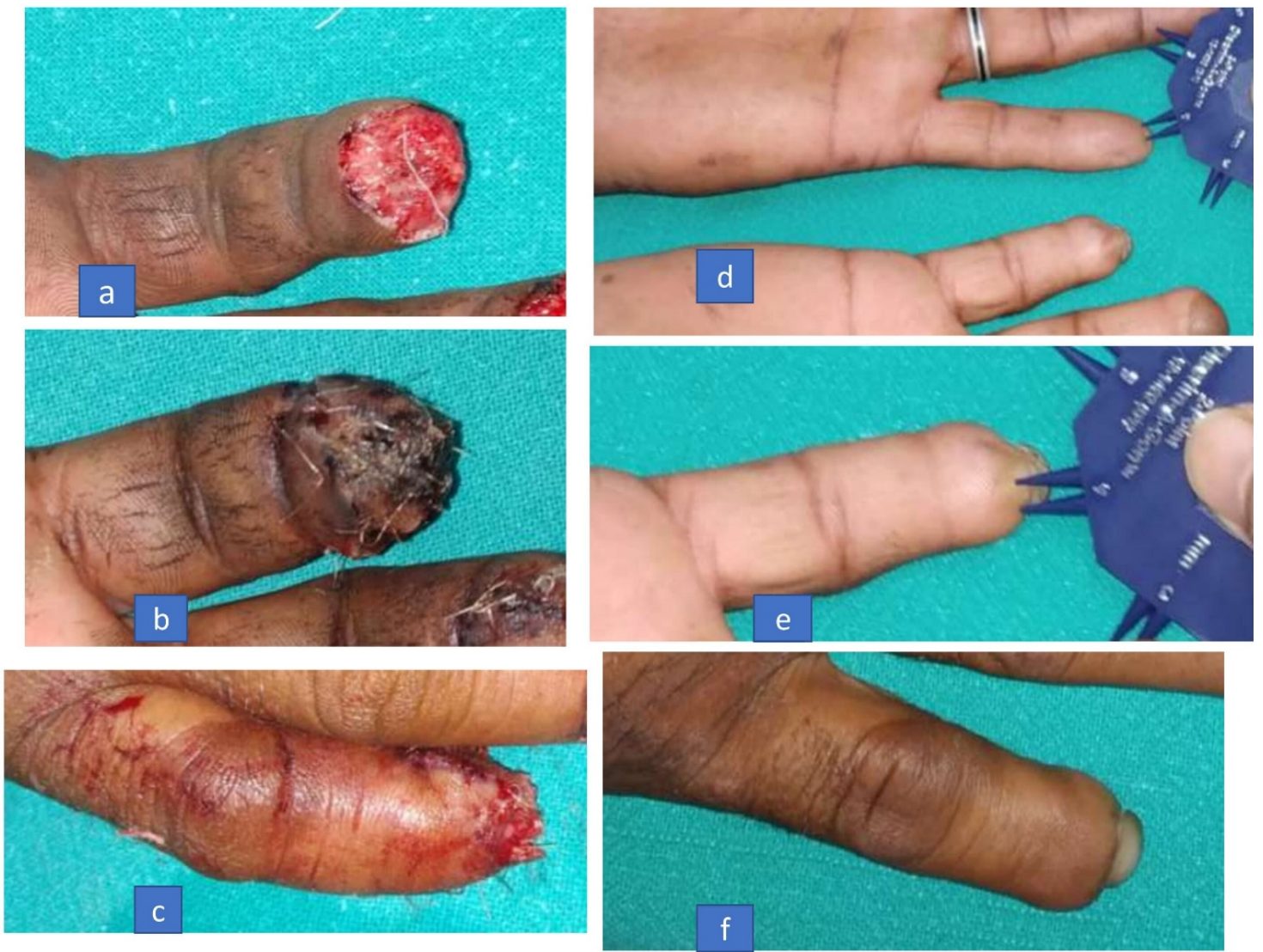

Fig. 2: Fingertip reconstruction with Kutler flap (a)Allen III amputation (b,c)volar \& dorsal view of reconstructed fingertip (d,e) measurement of $2 \mathrm{PD}$ of reconstructed \& contralateral fingertip (f)hook nail deformity
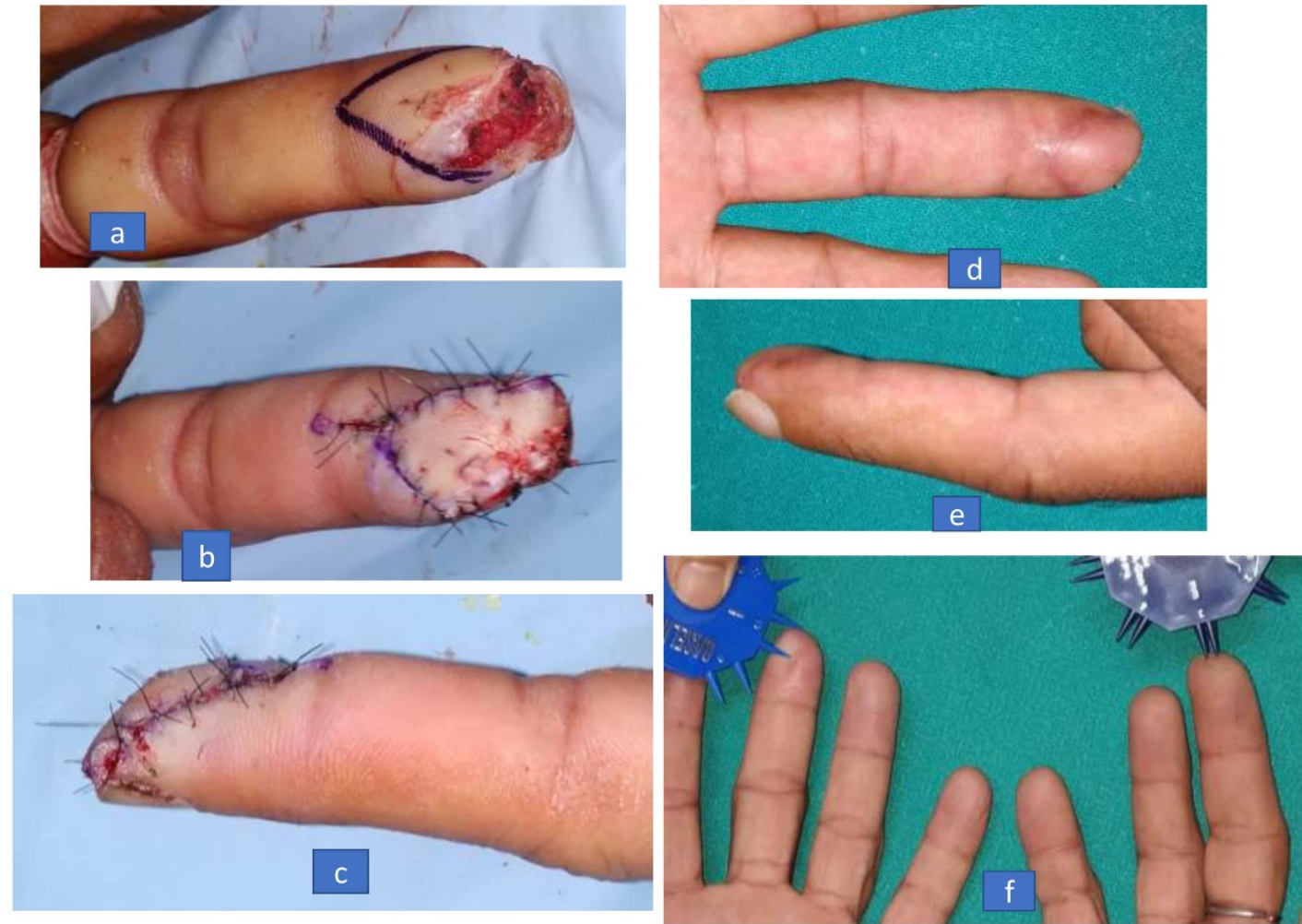

Fig. 3: Fingertip reconstruction with Atasoy flap (a)Allen II amputation (b-e)volar \& lateral views of immediate post-operative and 9 months follow up of reconstructed fingertip (f)comparison of $2 \mathrm{PD}$ of reconstructed with contralateral fingertip 
while all of them developed normal sensation and mobility. It is best indicated in transverse or dorsal oblique fingertip amputations.

Frieberg and Manktelow were the first to evaluate objectively the outcome of Kutler flap performed in their 30-fingertip amputations ${ }^{7}$. They achieved a mean two-point discrimination (2PD) of $6 \mathrm{~mm}$, and a good cosmetic recovery. Mean 2PD of 2.6 $\mathrm{mm}$ and $3.1 \mathrm{~mm}$ were reported in 32 fingertip reconstruction series in cases of Kutler and Kleinert flaps respectively ${ }^{8}$. Subsequently many authors evaluated neurosensory and functional outcomes of VY advancement flaps ${ }^{9,10}$. Frandsen in their prospective study performed 16 Kutler flaps and 12 Atasoy flaps for transverse fingertip amputation al level between distal one-third and one-half of nail bed $^{11}$. Apart from average time off work in between these two flaps, there was no significant difference in post-operative and late sequelae.

Biddulph introduced a modification in Kutler flap where he raised the triangular flaps with their neurovascular pedicle, midlaterally, for better mobilisation and reach ${ }^{12}$. Overall, 18 such patients were followed up for 1-3 years. Eight patients achieved normal 2PD and none had any tenderness. Parrot beaking developed in 3 patients. Using this technique, Krishnan performed 29-fingertip reconstruction ${ }^{13}$. He achieved a mean $2 \mathrm{PD}$ of $4.2 \mathrm{~mm}$ and $3.5 \mathrm{~mm}$ at 1 and 3 month follow up respectively $(P<0.0001)$. Standard Kutler flap can be advanced by $4-5 \mathrm{~mm}^{14}$. However, when dorsal incision is made up to depth of collateral ligament proximally and periosteum distally, while keeping volar incision only skin deep, advancement of 14 $\mathrm{mm}$ can be achieved. Ideal width be $7 \mathrm{~mm}$ and length up to $2-2.5 \mathrm{~cm}$. In 37 case series, there was no loss of flap. Sensibility was preserved in all.

Saito et al. were the first to suggest use of VY flap advancement with free full-thickness nail bed graft for fingertip reconstruction ${ }^{15}$. The long term aesthetic results of this technique was studied ${ }^{16,17}$. The use of volar VY advancement was extended in volar oblique fingertip amputations also, in his case series, and achieved $2-4 \mathrm{~mm}$ of $2 \mathrm{PD}$ with normal range of motion ${ }^{18}$. He introduced Snow's cupping technique, previously described for large volar advancement flap. The apex of volar triangular flaps reached proximal to distal interphalangeal joint (DIPJ), taking inspiration from Venkataswami ${ }^{19}$.

Moberg's palmar advancement and Atasoy's VY plasty was combined for successful thumb tip reconstruction in 2 patients ${ }^{20}$. This technique was further used in thumb tip reconstruction of 15 patients by Elliot $^{21}$. Based on their cadaveric study, Kumar and Satku proposed volar VY advancement flap with removal of distal $2 \mathrm{~mm}$ nail bed over terminal phalanx for "hook nail" deformity correction ${ }^{22}$. Ozyigit et al were the first to describe dorsal VY advancement flap for seven volar oblique or transverse finger amputations and were able to achieve mean $2 \mathrm{PD}$ of $4.7 \mathrm{~mm}^{23}$. All patients returned to work within 21 days. Bharathi reported use of volar VY advancement technique in 10 patients with dorsal oblique or transverse toe injuries ${ }^{24}$. After a mean 5 months follow-up all had excellent contouring and padding, with no wound complications or neuroma. Sungur et al introduced VY rotation advancement flap for 7 cases of fingertip amputations with successful results ${ }^{25}$. Lee et al used a combination of Atasoy's VY advancement flap with composite graft of amputee part, retaining bone, overlying nail bed and part of hyponychium, for reconstruction of fingertip amputation ${ }^{26}$. In the same year, Foo et al suggested transfixation of volar VY advancement flap with $0.8 \mathrm{~mm}$ Kirschner wire for 1-2 weeks, to improve fingertip contour and reach of the flap ${ }^{27}$. While in the following year, Foo and Arul proposed osteocutaneous VY flap in coronal oblique fingertip amputation to preserve length, provide nail, and bone reconstruction ${ }^{28}$. Chung and Foo presented two cases with a crescent flap for fingertip reconstruction with successful result ${ }^{29}$.

Zhou et al performed palmar VY flap combined with bone and nail bed grafts in 14 thumb tip amputations, and obtained a mean 2PD of $7.5 \mathrm{~mm}$ after a mean 12.8 months $^{30}$. MCP IP joint mobility loss was less than $10^{\circ}$. Diaz et al presented double VY flap for fingertip reconstruction and obtained a 2PD of $6-10 \mathrm{~mm}$ after 6 months of follow up in 7 patients ${ }^{31}$. It gives an additional $5 \mathrm{~mm}$ advancement than conventional VY flap. Arpaci et al performed "Super-Kutler flap" for 10 fingertips reconstruction and obtained a mean $2 \mathrm{PD}$ of $3.5 \mathrm{~mm}^{32}$. It was a homodigital island flap, in which cut ends of digital nerves were also repaired. In 2018, Viciana and Lessard proposed modifications in the Atasoy flap to increase its reach, like division of fibrous septa, dissecting flap from lateral to medial, avoiding coverage of nail bed, dissecting at mid flap level ${ }^{33}$. 
Haehnel et al reported outcomes of Atasoy flap at mean follow up of 4.7 years in 30 children with fingertip injuries, namely epicritical tactile sensitivity, deformities and scarring ${ }^{34}$. Appukuttan and Ragoowansi performed 10 cases of unilateral VY flaps, raised on perforator vessels, for fingertip reconstruction ${ }^{35}$. They obtained a $2 \mathrm{PD}$ of $3-4 \mathrm{~mm}$ after 6 months follow-up.

A wide range of mean $2 \mathrm{PD}$ were obtained in the various types of VY advancement flaps. We obtained marginally better 2PD in both groups, however intergroup difference was statistically insignificant $(P=0.42)$. In Atasoy flap passive ROM at DIPJ was affected significantly in comparison to control fingers. There was no statistically significant difference in cold intolerance in between both groups. We also obtained a satisfactory aesthetic outcome in both Kutler and Atasoy flaps.

\section{CONCLUSION}

VY advancement flap, namely Kutler flap and Atasoy flap, has proven their worth for fingertip reconstruction over time. They have been successfully used for Allen type II-IV fingertip amputations across the literature, along with some modifications. They are technically simple, easier and faster procedure, VY advancement flap had yielded good neurosensory, functional and aesthetic outcomes, with least complications and morbidities, requires only one stage and are robust flaps. However only defect size limits their use.

\section{ACKNOWLEDGEMENTS}

None declared.

\section{CONFLICT OF INTEREST}

The authors declare that they have no conflict of interest.

\section{STATEMENT OF FUNDING}

This study did not received any funding.

\section{REFERENCES}

1. K Sanjeev. Digital Amputations. In: Green's Operative Hand Surgery. 7th ed. Philadelphia: Elsevier; 2017; pp. 1709-17.
2. Ruijs ACJ, Jaquet JB, Daanen HAM, Hovius SER. Cold intolerance of the hand measured by the ciss questionnaire in a normative study population. $J$ Hand Surg Br 2006;31B(5):533-6. doi: 10.1016/j. jhsb.2006.04.013.

3. Rosas S, Paco M, Lemos C, Pinho T. Comparison between the Visual Analog Scale and the Numerical Rating Scale in the perception of esthetics and pain. Int Orthod 2017;15:543-60. doi: 10.1016/j. ortho.2017.09.027

4. Tranquilli-Leali E. Ricostruzione dellapice delle falangi ungueali mediante autoplastica volare peduncolata per scorrimento. Infort Traumatol Lav 1935; 1:186-93.

5. Kutler W. A new method for finger tip amputation. J American Med Assoc 1947;133(1):29. doi: 10.1001/ jama.1947.62880010007007.

6. Atasoy E, Ioakimidis E, Kasdan ML, Kutz JE, Kleinert HE. Reconstruction of the Amputated Finger Tip with a Triangular Volar Flap- A New Surgical procedure. J Bone Joint Surg Am 1970;52A(5):921-6.

7. Freiberg A, Manktelow R. The Kutler Repair For Fingertip Amputations. Plast Reconstr Surg 1972;50(4):371-5. doi: 10.1097/00006534197210000-00011.

8. Gellis M, Pool R. Two-Point Discrimination Distances In The Normal Hand And Forearm. Plast Reconstr Surg 1977;59(1):57-63. doi: 10.1097/00006534197701000-00010.

9. Weston PA, Wallace WA. The use of locally based triangular skin flaps for the repair of finger tip injuries. Hand 1976;8(1):54-8. doi: 10.1016/0072968x(76)90061-9.

10. Tupper J. Miller G. Sensitivity Following Volar V-Y Plasty for Fingertip Amputations. I Hand Surg Am 1985;10B(2):183-4. doi: 10.1016/02667681(85)90011-7.

11. Frandsen PA. V-Y Plasty As Treatment Of Fingertip Amputations. Acta Orthop Scand 1978;49:255-9. doi: 10.3109/17453677809005761.

12. Biddulph SL. The neurovascular flap in finger tip injuries. Hand 1979;2(1):59-63. doi: 10.1016/s0072968x(79)80011-x.

13. Krishnan KG. Sensory recovery after reconstruction of defects of long fingertips using the pedicled $\mathrm{V}$ flap. Br J Plast Surg 2001;54:523-7. doi: 10.1054/ bjps.2001.3647.

14. Shepard GH. The use of lateral V-Y advancement flaps for fingertip reconstruction. $J$ Hand Surg Am 1983;8(3):254-9. doi: 10.1016/s0363-5023(83)80153-1.

15. Saito H, Suzuki Y, Fujino K, Tajima T. Free nail bed graft for treatment of nail bed injuries of the hand. $J$ Hand Surg Am 1983;8(2):171-8. doi: 10.1016/s03635023(83)80010-0. 
16. Brown RE, Zook EG, Russell RC. Fingertip reconstruction with flaps and nail bed grafts. $J$ Hand Surg Am 1999;24(2):345-1. doi: 10.1053/ jhsu.1999.0345.

17. Sabapathy SR, Venkatramani H, Bharathi R, Jayachandran S. Reconstruction of Finger Tip Amputations with Advancement Flap and Free Nail Bed Graft. J Hand Surg Br 2002;27(2):134-8. doi: 10.1054/jhsb.2001.0695.

18. Furlow LT. V-Y "Cup" Flap for Volar Oblique Amputation of Fingers. J Hand Surg Br 1984;9(3):2536. doi: 10.1016/0266-7681(84)90036-6.

19. Venkataswami R, Subramanian N. Oblique Triangular Flap: A New Method of Repair for Oblique Amputations of the Fingertip and Thumb. Plast Reconstr Surg 1980;66:296-300.

20. Bang HH, Kojima T, Hayashi H. Palmar advancement flap with V-Y closure for thumb tip injuries. J Hand Surg Am 1992;17A:933-4. doi: 10.1016/03635023(92)90473-3.

21. Elliot D, Wilson Y. V-Y Advancement of the Entire Volar Soft Tissue of the Thumb in Distal Reconstruction. J Hand Surg. 1993;18B:399-402. doi: 10.1016/0266-7681(93)90073-o.

22. Kumar VP, Satku K. Treatment and prevention of "hook nail" deformity with anatomic correlation. J Hand Surg Am 1993;18(4):617-20. doi: 10.1016/03635023(93)90303-K.

23. Ozyigit MT, Turkaslan T, Ozsoy Z. Dorsal V-Y advancement flap for amputations of the fingertips. Scand J Plast Reconstr Surg Hand Surg 2007;41(6):3159. doi: 10.1080/02844310701463357.

24. Bharathi RR, Jose Jerome JT, Kalson NS, Sabapathy SR. V-Y Advancement Flap Coverage of Toe-Tip Injuries. J Foot Ankle Surg 2009;48(3):368-71. doi: 10.1053/j.jfas.2009.01.010.

25. Sungur N, Kankaya Y, Yildiz K, Dolen UC, Kocer U. Bilateral V-Y rotation advancement flap for fingertip amputations. Hand (N Y) 2012;7(1):79-85. doi: 10.1007/s11552-011-9389-6.

26. Lee SM, Rahman MF, Thirkannad S. Combination
V-Y Advancement Flap And Composite Graft For Reconstruction Of An Amputated Fingertip. Hand Surg 2012;17(1):145-9. doi: 10.1142/ S0218810412970015.

27. Foo TL, Wan KHM, Chew WYC. Safe and Easy Method to Preserve Fingertip Contour in VY-Plasty. Tech Hand Up Extrem Surg 2012;16(2):95-7. doi: 10.1097/BTH.0b013e31824e1fa2.

28. Foo TL, Arul M. Osteocutaneous VY Flap To Preserve Length In Coronal Oblique Fingertip Amputation. Hand Surg 2013;18(2):297-9. doi: 10.1142/ S0218810413970046.

29. Chung SR, Foo TL. Crescent Flap For Fingertip Reconstruction. Hand Surg 2014;19(3):459-61. doi: 10.1142/S021881041472037X.

30. Zhou X, Wang L, Mi J, Xu Y, Rui Y, Xue M, Shen X, Qiang L. Thumb fingertip reconstruction with palmar $\mathrm{V}-\mathrm{Y}$ flaps combined with bone and nail bed grafts following amputation. Arch Orthop Trauma Surg 2015;135:589-94. doi: 10.1007/s00402-015-2163-4.

31. Díaz LC, Vergara-Amador E, Fuentes Losada LM. Double V-Y Flap to Cover the Fingertip Injury. Tech Hand Up Extrem Surg 2016;20(4):133-6. doi: 10.1097/ BTH.0000000000000132

32. Arpaci E, Unlu RE, Altun S, Ertas NM. Super Kutler flap: an alternative technique for reconstruction of fingertip defects. J Hand Surg Eur Vol 2017;42(6):62632. doi: 10.1177/1753193416686884.

33. Viciana EJ, Lessard AS. Expanded Utilization of the Digital Atasoy Flap. Plast Reconstr Surg Glob Open. 2018;6(12):e2049. doi: 10.1097/ GOX.0000000000002049

34. Haehnel O, Plancq MC, Deroussen F, Salon A, Gouron $\mathrm{R}$, Klein C. Long-Term Outcomes of Atasoy Flap in Children With Distal Finger Trauma. J Hand Surg Am. 2019;44(12):1097.e1-1097.e6. doi: 10.1016/j. jhsa.2019.02.018.

35. Appukuttan A, Ragoowansi R. The unilateral perforator V-Y flap for fingertip reconstruction- a versatile technique. JPRAS Open 2019;23:1-7. doi: 10.1016/j.jpra.2019.10.004. 